EMBRYARIDDLE
Aeronautical University

SCHOLARLY COMMONS
International Journal of Aviation, Aeronautics, and Aerospace

\title{
Crew Resource Management for Large Unmanned Aircraft Systems Operations
}

\author{
Peter S. Neff \\ Middle Tennessee State University, peter.neff@mtsu.edu
}

Follow this and additional works at: https://commons.erau.edu/ijaaa

Part of the Aviation Safety and Security Commons, and the Management and Operations Commons

\section{Scholarly Commons Citation}

Neff, P. S. (2019). Crew Resource Management for Large Unmanned Aircraft Systems Operations. International Journal of Aviation, Aeronautics, and Aerospace, 6(3). DOI: https://doi.org/10.58940/ 2374-6793.1303

This Concept Paper is brought to you for free and open access by the Journals at Scholarly Commons. It has been accepted for inclusion in International Journal of Aviation, Aeronautics, and Aerospace by an authorized administrator of Scholarly Commons. For more information, please contact commons@erau.edu. 


\section{Crew Resource Management for Large Unmanned Aircraft Systems Operations}

\section{Cover Page Footnote}

Author Note Peter S. Neff, Department of Aerospace, Middle Tennessee State University Contributors Donald Crews, Department of Aerospace, Middle Tennessee State University Kevin Corns, Department of Aerospace, Middle Tennessee State University Correspondence concerning this article should be addressed to Peter S. Neff, Department of Aerospace, 1301 E. Main Street, MTSU Box 67, Murfreesboro, TN 37132 Contact: peter.neff@mtsu.edu 


\section{Introduction}

The objectives of this paper are to examine the importance of crew resource management (CRM) principles in the safe operation of unmanned aircraft systems (UAS) commercial flight operations and to emphasize the practical application of CRM principles to UAS commercial operations. The perspective of this paper is commercial flight operations for high altitude, long endurance (HALE) large UAS as defined by Arjomandi (2007), and that the Federal Aviation Administration (FAA) places in risk categories five to six (RC5 to RC6) as shown in Figure 1 (Ryan \& Larrow, 2017, p. 11)

- Falling Energy for Rotorcraft

- Cruise Speed and Mass used for fixed wing calculation

- Risk Classes 1-2 are primarily used under part 107.

- Risk Classes 1-3 should not require TC in the future, once Permit to Fly is in place.

- Risk Classes 4-6 are "typical" certification processes.

Table 12-1. Energ:-Based Classifications for U.AS.
\begin{tabular}{|c|l|}
\hline Risk Class & Kinetic Energy in Ft.Lb \\
\hline 1 & 5529 \\
\hline 2 & 2530 to $\$ 24,999$ \\
\hline 3 & 225,000 to $\$ 799,999$ \\
\hline 4 & 2800,000 to $\$ 5.999,999$ \\
\hline 5 & $26,000,000$ to $\$ 49,999,999$ \\
\hline 6 & $250,000,000$ and up \\
\hline
\end{tabular}

Figure 1. Note. Risk Classes (RC) Based on Kinetic Energy. Adapted from "FAA Building Blocks Leading to UAS Integration, Airworthiness and Operational Integration," by W. Ryan and J. Larrow, 2017, Russian FederalAir Transport Agency (FATA).

The current regulation governing UAS, 14 Code of Federal Regulations (CFR.) part 107, Small Unmanned Aircraft Operations, applies only to "the registration, airmen certification, and operation of civil unmanned aircraft systems within the United States" (Federal Aviation Administration, 2018a, para. 107.1). This regulation does not apply to air carrier operations (i.e., operations for hire), aircraft subject to the provisions of 14 CFR part 101(i.e., Moored Balloons, Kites, Amateur Rockets, Umanned Free Ballons, and Certain Model Aircraft), or remote 
pilot operations subject to the provisions of section 333 of public law 112-95 (United States Congress, 2012).

The orderly integration of UAS into the national airspace system (NAS) is a high priority of the congress and the Federal Aviation Administration (FAA) (Trump, 2018). The FAA formed the UAS Integration Pilot Program with the purpose of coalescing local, state, and federal government entities with private sector organizations to assist the Department of Transportation and the FAA to write regulations allowing the use of more complex UAS in joint use airspace (Federal Aviation Administration, 2018b). The program is charged with reviewing the following topics:

The IPP Lead Participants are evaluating a host of operational concepts, including night operations, flights over people and beyond the pilot's line of sight, package delivery, detect-and-avoid technologies and the reliability and security of data links between pilot and aircraft. Fields that could see immediate opportunities from the program include commerce, photography, emergency management, agricultural support and infrastructure inspections. (Federal Aviation Administration, 2018b, para. 3)

A successful program and promulgation of regulations applicable to the commercial operation of HALE UAS in RC5 to RC6 would eliminate the need for each operator to seek an exemption under section 333 of public law 112-95 (United States Congress, 2012).

The National Aeronautics and Space Administration (NASA) provided further imputus for the development of an industry, academic, and governmental partnership to promulgate regulatory protocols on June 13, 2018. NASA remotely piloted Ikhana, a civilian version of a MQ-9 Predator B UAS, without a chase plane in NAS Class A and Class E airspace to demonstrate joint use compatibility with a mix of manned aircraft traffic (Kooser, 2018; Northon, 2018). "Ikhana is a Native American Choctaw word meaning intelligent, conscious or aware" (Conner, 2015, para. 2). If long-range passenger and cargo transportation are added to the spectrum of large commercial UAS operations, the need for risk mitigation increases exponentially. It is critical that our academic, industrial, and regulatory sectors develop public policy to support their use to contribute to social, economic, and environmental well-being. The collaborative development and implementation of regulations covering HALE RC5 to RC6 UAS operations is a critical task of the UAS Integration Pilot Program because these types of large commercial UAS flight operations are on the horizon, and UAS will effect numerous social and economic changes in the near future.

According to Uzialko (2018), commercial UAS are currently used or forecast for future use in the areas listed in Table 1. 
Table 1

Commercial Uses for UAS

\begin{tabular}{ll}
\multicolumn{1}{c}{ Area } & \multicolumn{1}{c}{ Application } \\
\hline $\begin{array}{l}\text { Agriculture and } \\
\text { Forrest Management }\end{array}$ & $\begin{array}{l}\text { Crop management, Pest Infestation, } \\
\text { Vegitation management }\end{array}$ \\
\hline $\begin{array}{l}\text { Architecture and } \\
\text { Construction }\end{array}$ & 3D representations of intended structures \\
\hline Engineering & Site Survey \\
\hline $\begin{array}{l}\text { Enviornmental } \\
\text { Monitoring and } \\
\text { Conservation }\end{array}$ & $\begin{array}{l}\text { Monitor land and ocean wildlife migration } \\
\text { patterns, monitor water resources for } \\
\text { availability and for flood potential, and } \\
\text { monitor reclusive species }\end{array}$ \\
\hline Media and Insurance & Aerial footage of disaster areas \\
\hline Internet Access & Less expensive alternative to satellites \\
\hline
\end{tabular}

Note. Commercial UAS currently used or forecast for future use. Adapted from "10 Cool Commercial Drone Uses Coming to a Sky Near You, ' by A. C. Uzialko, 2018, Business News Daily. Retreived from https://www.businessnewsdaily.com

Although the current regulations do not provide for large civil commercial UAS operations, the flight of Ikhana demonstrated what is possible in the future of remotely piloted, large, commercial UAS. In addition to the commercial uses listed in Table 1, NASA researchers have forecasted their use in forest fire monitoring, emergency services, natural disaster monitoring, search and rescue operations, and large metropolitan traffic monitoring, in addition to law enforcement functions (Northon, 2018). Conceptualize the environmental impact of providing citizens with efficient traffic routing during rush hour or the monitoring of forest fire potential or water usage to ensure efficient crop hydration. A common thread in their utility is that they are used over large population centers or areas where there will be other air traffic congestion.

As can be seen from Figure 2, the MQ-9 is classified between RC5 and RC6 with a probability of catastrophic failure of $\times 10^{-8}$. This aircraft certification risk 


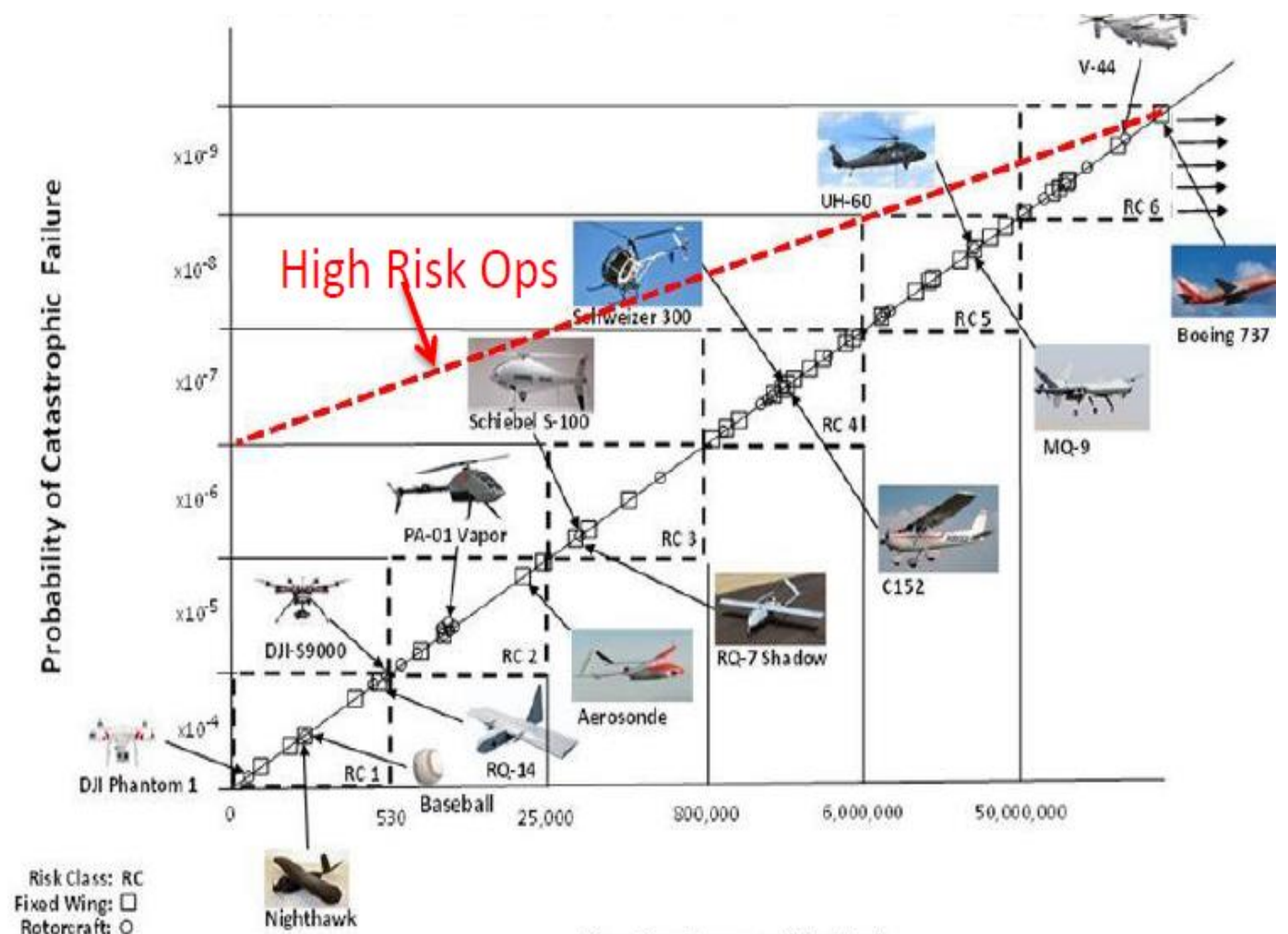

Rotoreraft: 0

NOTE: Not drawn to scale. For illustration only.

Kinetic Energy (Ft-Lbs)

Figure 2. Fixed Wing and Rotorcraft Probability of Catastrophic Failure vs. Kinetic Energy. Adapted from "Unmanned Systems Certification” by W. Ryan, 2017, Committee on Assessing the Risks of Unmanned Aircraft Systems (UAS) Integration. Retrieved from http://sites.nationalacademies.org/DEPS/ ASEB/DEPS_180887

calculation is determined through consideration of the operator' concept of operation as well as the airspace and area of operation proposed (Ryan \& Larrow, 2017). Human factors influence every aspect of the risk determination of UAS operations. Humans design, manufacture, test, maintain, and program the vehicle for autonomous flight or remotely pilot the vehicle for the assigned mission. There are numerous elements to be considered in order to reduce the risk of human error in every phase of the design, build, operate process to include training, mentoring, and quality control. In fixed and rotary wing flight operations, CRM has proven to be an instrumental element in the reduction of accidents as demonstrated by the decreasing slope of the curve from 1998 to 2013 shown in Figure 3. 


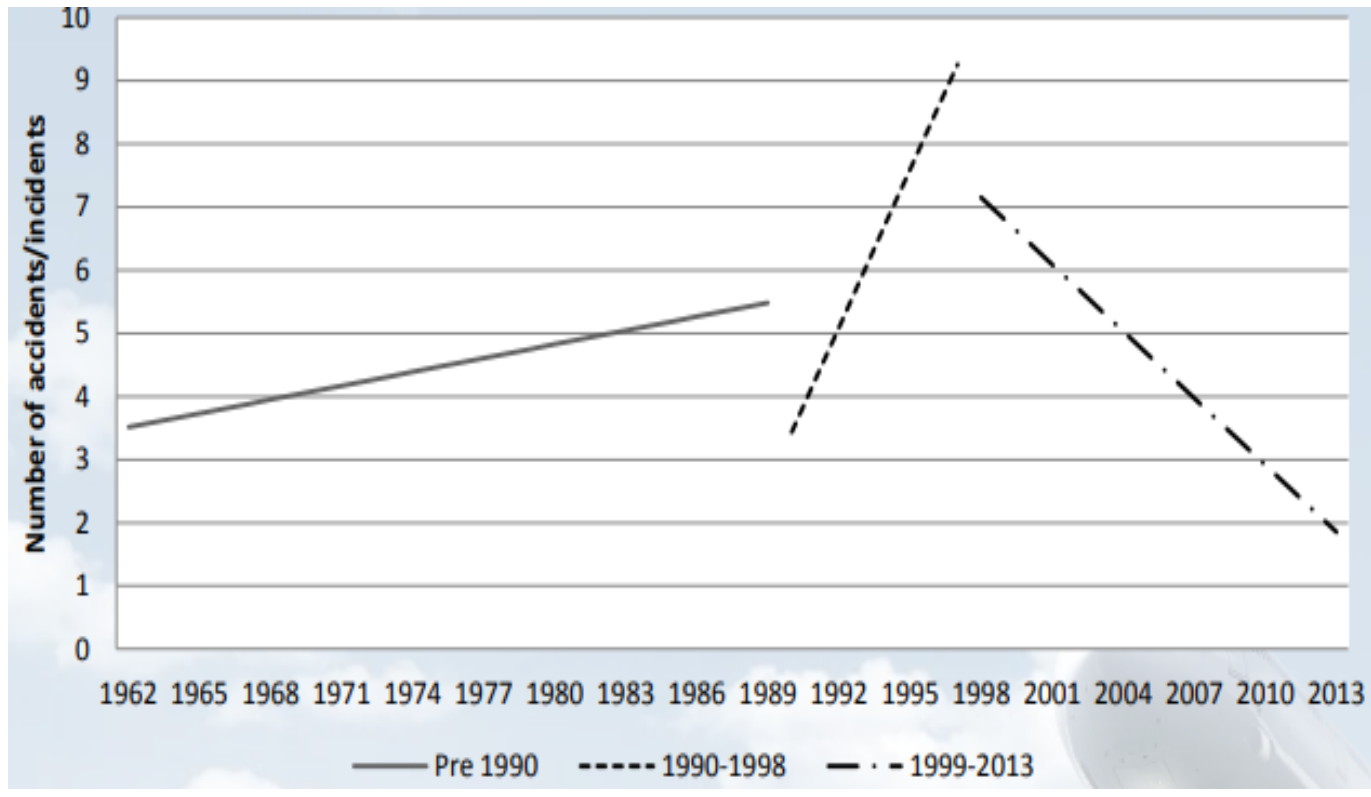

Figure 3. The Transformation of CRM-based Training and it [sic] Effects on Aviation Safety in the U.S. from 1960 to 2013. Adapted from "The Transformation of CRM-Based Training and it[sic] Effects on Aviation Safety in the U.S. from 1960 to 2013, " by L. Rudaei et al., 2015. Retrieved from https://flight Safety.org

To date, the FAA has followed a gradual development of the regulatory structure governing the operation of UAS. The FAA should be more proactive in developing the regulatory structure due to the rapid development of new and innovative technologies in the field as demonstrated by the remotely piloted, unescorted flight of Ikhana in congested airspace over Southern California. Although human factors touch every aspect of the UAS, this research was confined to operational human factors errors through a case study of four MQ-9 accidents and a subsequent cross-case analysis. The cross-case analysis identified the eight most prevalent human factors errors in the four-accident data set. The errors identified were a mixture of soft-skill and hard-skill errors. Additionally, a review of a study completed by Sharma and Chakravarti (2005) reinforced the results of the cross-case analysis and added supplementary soft-skill human factors errors. The training and implementation of CRM principles into an overall safety management system to mitigate human factors errors in large UAS in the RC5 to RC6 categories will result in a reduction of the operational risk in the same manner as in fixed and rotary wing flight operations. 


\section{Literature Review}

\section{Four-Case Cross-Case Analysis Significant Human Factors Errors}

Neff (2016) completed a cross-case study of four large RC5 to RC6 UAS (i.e., MQ-9) accidents using the Human Factors Analysis and Classification System (HFACS) template developed by Wiegman and Shappell (2003) as the theoretical framework for the analysis. HFACS is inclusive of organizational culture, hard flying skills, and soft-skills such as communication and decision making. The cross-case HFACS analysis of the four accidents yielded 17 risk factors. A Pareto Analysis of the 17 risk factors yielded the eight highest risk (i.e., most prevalent) human factors errors indicated in Table 2.

Table 2

Four-Case Cross-Case Analysis Significant Human Factors Errors

\begin{tabular}{|c|c|c|c|c|c|c|c|c|c|}
\hline & & Code & NV & $\mathbf{A Z}$ & S4.12 & $\begin{array}{c}\text { S12.1 } \\
1 \\
\end{array}$ & $\begin{array}{l}\text { Total } \\
\text { Risk }\end{array}$ & CUM & $\%$ \\
\hline 1 & Skill-Based Errors & 1.12 & 25 & 16 & 20 & 16 & 77 & 77 & 18.0 \\
\hline 2 & Decision Errors & 1.11 & 12 & 16 & 12 & 12 & 52 & 129 & 31.0 \\
\hline 3 & $\begin{array}{l}\text { Technological } \\
\text { Environment }\end{array}$ & 2.12 & 15 & 15 & 9 & 8 & 47 & 176 & 42.0 \\
\hline 4 & $\begin{array}{l}\text { Communication \& } \\
\text { Coordination }\end{array}$ & 2.31 & 8 & 4 & 20 & 4 & 36 & 212 & 50.0 \\
\hline 5 & $\begin{array}{l}\text { Failure to Correct } \\
\text { Known Problem }\end{array}$ & 3.3 & 10 & 15 & 5 & 5 & 35 & 247 & 59.0 \\
\hline 6 & $\begin{array}{l}\text { Organizational } \\
\text { Climate }\end{array}$ & 4.2 & 5 & 20 & 5 & 5 & 35 & 282 & 67.0 \\
\hline 7 & $\begin{array}{l}\text { Inadequate } \\
\text { Supervision }\end{array}$ & 3.1 & & 8 & 8 & 8 & 24 & 306 & 73.0 \\
\hline 8 & Routine Violations & 1.21 & 4 & 10 & 5 & & 19 & 325 & 77.0 \\
\hline
\end{tabular}

Note. This table is a compilation of the data presented in the analysis of each accident in the four-accident data set. Adapted from "Unmanned Aircraft Systems: The Mitigation of Human Factors Errors Through Training," by P. Neff, 2016. Retrieved from ProQuest Dissertations Publishing.

These eight human factors account for $77 \%$ of the reviewed four-case UAS accident set. Neff (2016) selected the four-case UAS accident set because all the 
aircraft were MQ-9 Predator B aircraft. Coincidentally, Ikhana is the civilian version of the MQ-9. Three of the accident aircraft were flown by civilian commercial pilots under contract to a federal government organization while one accident aircraft was flown by a U.S. Air Force pilot. Current federal regulations do not provide for civilian commercial UAS of this size operated in the U.S. NAS. However, the time when the operation of this size or larger UAS will be routine in joint use airspace in the NAS is close at hand. In order to ensure the safety of all operators in the NAS, CRM should be part of an overall safety management system implemented and practiced by all operators and overseen by the FAA.

\section{Risk Calculation}

The tables were constructed using a frequency $(f)$ and severity $(\mathrm{S})$ multiplier to weight the prevalence of the various human errors. A scale of 1 to 5, extremely improbable to frequent, ranked frequency $(f)$. Similarly, a scale of 1 to 5, negligible to catastrophic, ranked severity $(\mathrm{S})$. For the purpose of representing relative risk, a maximum frequency of 5 and maximum severity of 5 were selected to derive a maximum risk factor of 25. A compilation of all risk factors in the four-accident data set identified 17 human factors errors yielding a total risk factor of 421 (Neff, 2016). The risk calculation to determine the eight most prevalent human errors was based on the total of the 17 identified errors. Referencing Table 2, skill-based error scored a risk factor of 77 based on the total risk factor for skill-based errors of all four accidents. Seventy seven divided by 421 yields a risk percentage of $18 \%$ indicating that there is an $18 \%$ chance that skill-based errors were contributory to the accident. The Pareto Analysis determined the eight most prevalent errors listed in Table 2 and that skill-based errors were the leading causal factor in the fouraccident data set studied by Neff (2016).

\section{Indian Air Force Five-Case Accident Analysis}

A second study reviewed by Neff (2016) and completed by Sharma and Chakravarti (2005) analyzed five Indian Air Force UAS accidents. The results of their study identified eight themes relating to the causal role of the misapplication of soft skills in the accidents and are presented in Table 3. Their analysis placed emphasis on the inputs of communication and workload management to teamwork and on the output of teamwork consisting of situational awareness. Although Sharma and Chakravarti (2005) did not mention threat and error management specifically, they included leadership and decision making in their analysis as causal soft skills; both of which are foundations of threat and error management. The research conducted by Sharma and Chakravarti (2005) confirms several of the eight human factors errors listed in Table 2 determined by Neff (2016), and it 
identifies other primarily soft skill human factors errors not present in the Neff study.

As can be seen from Table 2, Neff's (2016) four-aircraft accident case study lists communications and coordination errors as the fourth most significant error contributing an overall $8.6 \%$ risk as an accident causal factor. Sharma and Chakravarti's (2005) five-accident case study represented in Table 3 placed communication as the seventh greatest risk factor.

Table 3

India DGAC Case Study Derived Human Factors Errors (Sharma \& Chakravarti, 2005)

\begin{tabular}{ccl}
\hline Number & Human Factors Error & \multicolumn{1}{c}{ Comments } \\
\hline 1 & Decision-making & $\begin{array}{l}\text { Pilots reverted to early learning in the event of a systems } \\
\text { emergency resulting in loss of the airframe. } \\
\text { System automation and redundency created a false sense of } \\
\text { operational security. }\end{array}$ \\
\hline 2 & Situational Awareness & $\begin{array}{l}\text { Long periods of monitoring aircraft position and systems } \\
\text { parameters caused pilots to lose focus and alarms or alerts went } \\
\text { unoticed. }\end{array}$ \\
\hline 3 & Workload & $\begin{array}{l}\text { Emergency situation task saturation varied with pilot skill set, } \\
\text { experience, and critical thinking ability. }\end{array}$ \\
\hline 5 & Stress & $\begin{array}{l}\text { Applied conflicting procedures when faced with an actual } \\
\text { emergency scenario versus a training scenario. }\end{array}$ \\
\hline 6 & Teamwork & $\begin{array}{l}\text { Success as a team and CRM requires successful resolution of } \\
\text { conflict between the team members, communication skills, } \\
\text { setting expected cockpit norms, and critical thinking leading to } \\
\text { decisive action plans. }\end{array}$ \\
\hline
\end{tabular}

Note. Adapted from "Unmanned Aircraft Systems: The Mitigation of Human Factors Errors Through Training," by P. Neff, 2016. Retrieved from ProQuest Dissertations Publishing.

\section{Importance of CRM to Safety in Commercial Manned or Unmanned Flight Operations}

As cited by Neff (2016), Lacagnina, Rosenkrans, Werfelman, and Darby (2003) identified four mitigations: (a) crew resource management, (b) standard operating procedures, (c) professional culture, and (d) safety regulation applied by operators to improve safety in the airline cockpit. CRM was developed in the 1970s in response to research data that indicated the majority of airline accidents were caused by human error versus mechanical failure. These mitigations apply equally 
to large commercial UAS flight operations. They emphasized the importance of crew resource management as foundational to safe flight operations.

\section{Concepts of CRM for Future UAS Operations}

CRM embodies the concept of efficiently managing all of the available resources (Federal Aviation Administration, 2004). Technical flying skills constitute one of the elements foundational to safe flight operations. The tenets of CRM focus on the effective use of soft skills such as interpersonal communication, decision-making, leadership, problem solving, threat and error management, task allocation, and maintaining situational awareness (SKYbrary, 2018). All of these skills are human skills which if not learned and practiced might become human errors. CRM is one of the elements of a safety program that encourages effective collaborative thought and mitigates the deleterious effects of human errors, incorrect human responses to threats, such as poor communication, multi-tasking, loss of orientation, and failure to recognize potential threats to safe flight operations.

Based on a review of the CRM course descriptions of three major universities with large aviation programs, communications, workload management, and situational awareness constitute the subject areas emphasized during the course. Additionally, Dahlstrom, Laursen, and Bergstrom (2008) described the relationship of threat and error management and CRM when they stated "The concept has been described in many different ways, including it being a new generation of CRM or even an alternative to CRM" (p. 20). This research included threat and error management (TEM) in the CRM model represented in Figure 4 based on the premise that "...the overarching justification for CRM should be error management" (Helmreich, Merritt, \& Wilhelm, 1999, p. 27). Cusick, Cortes, and Rodrigues (2017) reinforced the inclusion of TEM in the CRM framework when they noted "...the sixth generation of CRM was formed, which introduced the Threat and Error Management (TEM) framework as a formalized approach for identifying sources of threats and preventing them from impacting safety at the earliest possible time" (p.131).

To codify the concepts, a visual representation of the CRM framework represented in Figure 4 identifies communication and workload management as inputs to the collaborative thought process of teamwork while situational awareness and threat and error management constitute the outputs. 


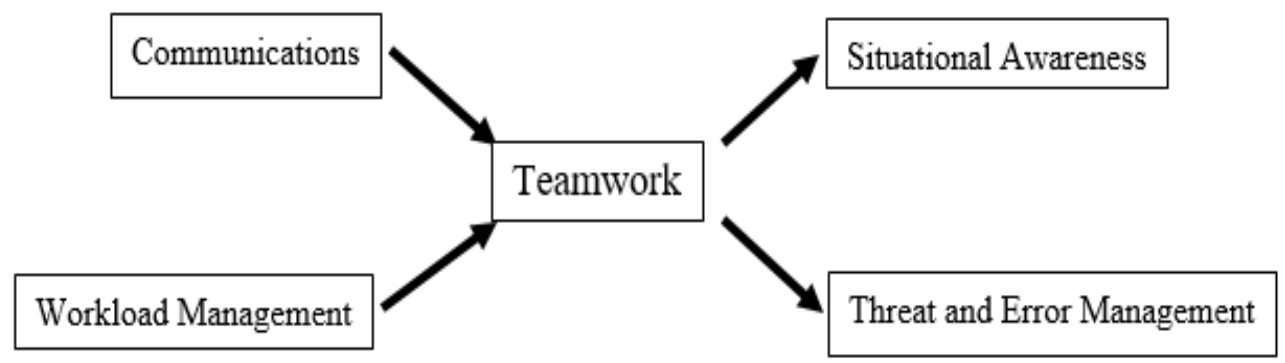

Figure 4. Visual representation of the CRM model framework.

The elements of communications, workload management, situational awareness, threat and error management, and teamwork represent a transition that occurs when individual soft skills are utilized to aggregate a team approach to achieve safe flight operations. The FAA considers the acquisition of CRM skills to be "...an integral part of training and [flight] operations" (Federal Aviation Administration, 2004, Purpose section, para. 1). Although the FAA considers CRM skills to be a critical element in safe flight operations, the administration does not specifically address CRM in the area of UAS flight operations. The purpose of this paper is to explore the applicability of CRM principles as operational tenets to multi-crew commercial UAS flight operations for integration into a safety management system in order to achieve a high level of safety.

\section{Methodology}

The study overlaid the accident causal factors determined by Neff (2016) represented in Table 2 and the accident causal factors determined by Sharma and Chakravarti (2005) shown in Table 3 against the CRM subject map represented in Figure 4. The result was an identification of the CRM elements with their associated potential accident causal risks that were not applied. If the CRM elements had been applied, the human errors might have been mitigated and the accident might not have occurred.

\section{Human Factors Errors in Large UAS Flight Operations}

Nogales, AZ April 26, 2006. The U.S. Border Patrol loss of an MQ-9 at Nogales, AZ on April 26, 2006, was the first UAS accident investigated by the NTSB (National Transportation Safety Board, 2007). The accident aircraft was flown by a civilian commercial pilot under contract to the Border Patrol. The NTSB 
cited inadequate training, inadequate supervision, normalization of deviation, and workload management as contributing causes (National Transportation Safety Board, 2007). An analysis using the HFACS template identified 13 separate human factors causal factors. A Pareto analysis yielded the eight factors shown in Table 4 that accounted for $82 \%$ of the causal factor risk (Neff, 2016).

Table 4

Risk Factor Calculation U.S. Border Patrol Accident April 26, 2006, Nogales, AZ

\begin{tabular}{lccccccc}
\hline & HF Sub-Category & Code & $f$ & S & $\begin{array}{c}\text { Risk } \\
\text { Factor }\end{array}$ & CUM & \% \\
\hline $\mathbf{1}$ & Organizational Climate & 4.2 & 4.0 & 5 & 20 & 20 & $15 \%$ \\
$\mathbf{2}$ & Decision Errors & 1.11 & $3.5(4)$ & 4 & 16 & 36 & $27 \%$ \\
$\mathbf{3}$ & Skill-Based Errors & 1.12 & 4.0 & 4 & 16 & 52 & $40 \%$ \\
$\mathbf{4}$ & Failure to Correct Known & 3.3 & $2.5(3)$ & 5 & 15 & 67 & $51 \%$ \\
$\quad$ Problem & & & & & & \\
$\mathbf{5}$ & Technological Environment & 2.12 & 5.0 & 3 & 15 & 82 & $63 \%$ \\
$\mathbf{6}$ & Routine Violations & 1.21 & 2.0 & 5 & 10 & 92 & $70 \%$ \\
$\mathbf{7}$ & Supervisory Violation & 3.4 & 2.0 & 4 & 8 & 100 & $76 \%$ \\
$\mathbf{8}$ & Inadequate Supervision & 3.1 & 2.0 & 4 & 8 & 108 & $82 \%$ \\
\hline
\end{tabular}

Note. As an example, the organizational climate risk factor of 20 used a frequency "f" of 4.0 and a severity "S" of 5 (i.e., 4.0 x $5=20$ ). Adapted from "Unmanned Aircraft Systems: The Mitigation of Human Factors Errors Through Training," by P. Neff, 2016. Retrieved from ProQuest Dissertations Publishing.

Seychelles Islands, December 13, 2011. The U.S. Air Force MQ-9A accident aircraft was flown under contract to the U.S. Air Force by a civil commercial pilot. The aircraft suffered an engine malfunction shortly after takeoff. The pilot elected to execute a return to the departure airport. The subsequent high speed approach and landing resulted in a runway overrun and the destruction of the aircraft. The U.S. Air Force Accident Investigation Board (USAFAIB) cited several probable causes including pilot proficiency and decision making (Jaquish, 2011). An HFACS analysis of the accident yielded 11 contributing human factors with the seven significant human factors shown in Table 5. A Pareto analysis resulted in the seven significant human factors errors noted in Table 5 accounted for $78 \%$ of the risk (Neff, 2016). 
Table 5

Risk Factor Calculations USAF Accident December 13, 2011, Seychelles Islands

\begin{tabular}{|c|c|c|c|c|c|c|c|}
\hline & HF Sub-Category & Code & $f$ & $\mathbf{S}$ & $\begin{array}{c}\text { Risk } \\
\text { Factor }\end{array}$ & Cum & $\%$ \\
\hline 1 & Skill-Based Errors & 1.12 & $3.5(4)$ & 4 & 16 & 16 & $20 \%$ \\
\hline 2 & Decision Errors & 1.11 & $2.5(3)$ & 4 & 12 & 28 & $34 \%$ \\
\hline 3 & Organizational Process & 4.3 & $1.5(2)$ & 4 & 10 & 38 & $46 \%$ \\
\hline 4 & Inadequate Supervision & 3.10 & $1.5(2)$ & 4 & 8 & 46 & $56 \%$ \\
\hline 5 & $\begin{array}{l}\text { Technological } \\
\text { Environment }\end{array}$ & 2.12 & $1.5(2)$ & 5 & 8 & 54 & $66 \%$ \\
\hline 6 & Organizational Climate & 4.2 & 1.0 & 5 & 5 & 59 & $72 \%$ \\
\hline 7 & $\begin{array}{l}\text { Failure to Correct Known } \\
\text { Problem }\end{array}$ & 3.3 & 1.0 & 5 & 5 & 64 & $78 \%$ \\
\hline
\end{tabular}

Note. Adapted from "Unmanned Aircraft Systems: The Mitigation of Human Factors Errors Through Training," by P. Neff, 2016. Retrieved from ProQuest Dissertations Publishing.

Seychelles Islands, April 4, 2012. The U.S. Air Force MQ-9A aircraft crashed in the Seychelles Islands in April 2012, four months following the crash in the Seychelles of a another MQ-9A. This aircraft was also flown by a civilian commercial pilot. The pilot accidently shut the engine down after takeoff and was forced to attempt an on-airport landing without engine power. The pilot did not complete proper checklists, follow standard operating procedures, and failed to configure the aircraft for landing. After a landing gear up arrival, the aircraft left the runway and came to rest in the Indian Ocean 4 minutes and 15 seconds after takeoff (Echternacht, 2012). The USAFAIB again cited a lack of proficiency as a contributing cause (Echternacht, 2012). An HFACS analysis of the accident identified 14 potential human factors errors that contributed to the accident while the nine human factors errors shown in Table 6, based on a Pareto analysis, accounted for $80 \%$ of the contributory accident risk (Neff, 2016). 
Table 6

Risk Factor Calculations USAF Accident April 4, 2012, Seychelles Islands

\begin{tabular}{|c|c|c|c|c|c|c|c|}
\hline & HF Sub-Category & Code & $f$ & $\mathbf{S}$ & $\begin{array}{c}\text { Risk } \\
\text { Factor }\end{array}$ & CUM & $\%$ \\
\hline 1 & Skill-Based Errors & 1.12 & $\begin{array}{l}13.75 \\
(14)\end{array}$ & 4 & 20 & 20 & $17 \%$ \\
\hline 2 & $\begin{array}{l}\text { Communication \& } \\
\text { Coordination }\end{array}$ & 2.31 & 5 & 4 & 20 & 40 & $34 \%$ \\
\hline 3 & Decision Based Errors & 1.11 & $2.25(3)$ & 4 & 12 & 52 & $44 \%$ \\
\hline 4 & Exceptional Violations & 1.22 & $1.75(2)$ & 5 & 10 & 62 & $53 \%$ \\
\hline 5 & Technological Environment & 2.12 & 3 & 3 & 9 & 71 & $61 \%$ \\
\hline 6 & Inadequate Supervision & 3.1 & 2 & 4 & 8 & 79 & $68 \%$ \\
\hline 7 & Fitness for Duty & 2.32 & $0.75(1)$ & 5 & 5 & 84 & $72 \%$ \\
\hline 8 & Organizational Climate & 4.2 & $0.5(1)$ & 5 & 5 & 89 & $76 \%$ \\
\hline 9 & $\begin{array}{l}\text { Planned Inappropriate } \\
\text { Operations }\end{array}$ & 3.2 & $0.5(1)$ & 5 & 5 & 94 & $80 \%$ \\
\hline
\end{tabular}

Note. Adapted from "Unmanned Aircraft Systems: The Mitigation of Human Factors Errors Through Training," by P. Neff, 2016. Retrieved from ProQuest Dissertations Publishing.

Douglas County, NV, December 5, 2012. The mishap aircraft, an MQ-9 Reaper, was piloted by a U.S. Air Force pilot on a training mission in the vicinty of Las Vegas, NV. The USAFAIB found that some of the cockpit controls were not properly set during the preflight inspection. This anomoly was attributed to the fact that the mission crew did not perform the preflight inspection instead they relied on another crew to complete the preflight checklist. This practice was noted as common among the crews and violated standard operating procedures constituting a normalization of deviation. As a result of this practice on this flight, the aircraft propeller went into reverse pitch every time the throttle was selected to a position outside of full thrust. The aircraft stalled and impacted the ground resulting in a total loss (Grace, 2012). An HFACS analysis of the accident indicated 12 human factors accident risks to include inadequate supervision, pilot skill-based errors, poor decision making, and inadequate crew workload management (Neff, 2016). A Pareto analysis yielded the seven risks listed in Table 7 representing $78 \%$ of the total risk factors. 
Table 7

Risk Factor Calculations USAF Accident December 5, 2012, Douglas County, Nevada

\begin{tabular}{|c|c|c|c|c|c|c|c|}
\hline & HF Sub-Category & Code & $f$ & $\mathbf{S}$ & Risk & $\begin{array}{l}\text { Cum } \\
\text { Risk }\end{array}$ & $\%$ \\
\hline 1 & Skill-Based Errors & 1.12 & $7.5(8)$ & 4 & 25 & 25 & $24 \%$ \\
\hline 2 & Technological Environment & 2.12 & 6.0 & 3 & 15 & 40 & $38 \%$ \\
\hline 3 & Decision Errors & 1.11 & $2.5(3)$ & 4 & 12 & 52 & $49 \%$ \\
\hline 4 & $\begin{array}{l}\text { Failure to Correct Known } \\
\text { Problem }\end{array}$ & 3.3 & 2.0 & 5 & 10 & 62 & $58 \%$ \\
\hline 5 & $\begin{array}{l}\text { Communication \& } \\
\text { Coordination }\end{array}$ & 2.31 & 2.0 & 4 & 8 & 70 & $66 \%$ \\
\hline 6 & Perceptual Errors & 1.13 & 2.0 & 4 & 8 & 78 & $74 \%$ \\
\hline & Organizational Climate & 4.2 & 1.0 & 5 & 5 & 83 & $78 \%$ \\
\hline
\end{tabular}

Note. Adapted from "Unmanned Aircraft Systems: The Mitigation of Human Factors Errors Through Training," by P. Neff, 2016. Retrieved from ProQuest Dissertations Publishing.

\section{Communication}

\section{CRM Elements}

Communication and coordination issues were the second most prevalent risk factor that contributed to the April 4, 2012, Seychelles Islands accident a risk factor of 20 as indicated in Table 7. Additionally, communications and coordination was the fifth most prevalent risk factor in the USAF Douglas County, NV MQ-9 accident. As presented in the Table 2 cross-case analysis (Neff, 2016) and Sharma and Chakravarti's (2005) five-accident analysis in shown in Table 3, communications issues were the fourth and seventh, respectively, leading causal factors in the accidents studied. Practiced CRM skills might have mitigated the communications causal factors.

As an underlying element of CRM and an input to teamwork, good communication involves a speaker, a clear message, and a receiver. A common language consisting of standard terminology and expected standard operating procedures for a given set of circumstances reinforces the team concept. Use of "we" language when the pilot-in-command solicits input and informs other crewmembers and acknowledges all decisions gained through an open and interactive operating environment improves communication. Additionally, 
standard callouts serve as check-in communication during periods of high operational stress and low communication.

The importance of clear communication between and among various crews operating a single UAS in the takeoff, landing, and mission phases is a critical element of mission success. Without the drag disadvantage of external stores, mission duration might approach 30 hours in a civil commercial tasking (Wheeler, 2012). A duration of this length will require several crew changes at both crew positions (i.e., pilot and sensor operator) as well as personnel in the ground support cadre of up to 171 persons (Wheeler, 2012).

\section{Workload Management}

In Sharma and Chakravarti's (2005) five-accident analysis in shown in Table 3, elements of workload presented in the study included critical thinking/decision making and task saturation based on pilot skills. Workload management ranked as the third most prevalent accident causal factor. Neff (2016) represented workload management through the basic elements of decision making and [pilot] skill-based errors. These combined errors were prevalent in each of the four accidents and represented $31 \%$ of the accident risk as indicated in Table 2 . The proportion of accident risk strongly indicates the criticality of integrating workload management skills into a CRM training program for large commercial civil UAS operators through scenario based abnormal and emergency situations. These scenarios should precipitate task saturation representative of the causal factors present in each of the four cohort accidents.

Time management is synchronous with successful task accomplishment. As with all tasks, concentration on the task at hand while reducing distractions and being open to ideas and opinions from other team members assists in the distribution of the workload.

Critical to workload management is the use of standard operating procedures (SOP). SOP embody the element of risk analysis and represent the least risk option appropriate for the circumstance. As such, reliance on SOP reduces the workload and establishes a natural task prioritization. A CRM program emphasizing proactive workload management prevents task saturation and facilitates effective, as well as efficient, team member completion of assigned tasks.

\section{Teamwork}

McEwan, Ruissen, Eys, Zumbo, and Beauchamp (2017) provided a very comprehensive definition of teamwork that embodies the concepts of ...interactive and interdependent behavioral processes among team members" ( $p$.

2). In the CRM model framework, the interdependent and interactive processes 
include communication and workload management inputs. McEwan et al. (2017) further characterized outputs such as team performance to be the result of teamwork. The authors cite the collaborative working environment prevalent in a crew working through a technical issue or a weather problem as an example of aviation teamwork.

In the aviation CRM model framework, foundational teamwork skills include clear, concise briefings that establish individual tasks and performance expectations as well as operational limits. Additionally, the concepts of teamwork emphasize mutual respect for the input of each crewmember demonstrated by the practice of using inclusive language such as the term "we."

Further, an important aspect of teamwork emphasized in the model is the debriefing of individual or team performance. Performance outputs consist of team situational awareness and team threat and error management. These concepts should be fundemental in UAS flight operations because flight crews often consist of a takeoff and landing crew and multiple enroute crews. In these critical phases of flight, situational awareness and threat and error management outputs of teamwork assume a high degree of importance due to the aircraft proximity to the ground and to the transitioning configurations. The reverse is true of the recovery phase of the aircraft. Some aircraft will be able to stay airborne for extended periods of time in the enroute phase over population centers providing essential services for extended periods of time. This mission will require multiple crews to fly the aircraft over the duration of the mission.

Anticipated operational protocols will likely require several teams to operate the UAS. Sharma and Chakravarti (2005) specifically identified teamwork as an evaluated element in their five-UAS accident study as the fifth contributing factor to the cohort of accidents studied. Neff (2016) dissected teamwork into components including decision errors, communication and coordination, failure to correct known problems, routine violations (i.e., normalization of deviation), and inadequate supervision. A combined accident causal risk factor of $39.5 \%$ of these elements of teamwork derived from Table 2 point to the importance of teaching effective teamwork skills as an element of a safety management system implemented by large commercial civil UAS operators.

\section{Situational Awareness}

Situational awareness is also frequently characterized as a common mental model. In aviation terms, this means that the flight crew shares a common perception of the current and future flight environment and trajectory of the aircraft. Situational awareness is enhanced through pertinent and timely briefings using common language to ensure understanding of the current and future operating environment and to maintain an open and interactive operating atmosphere. The 
open and interactive operating environment encourages crewmember advocacy and the validation of the common mental model.

Continued situational awareness is foundational to safe UAS flight operations. According to Merlin (2013), "[Remotely Piloted Aircraft] RPA operators are subject to impaired situational awareness as a result of several factors" (p.127). The situational awareness challenges to UAS pilots include flying the RPA through the use of cameras. The cameras provide a restricted view of the flight environment compounded by the limiting capabilities of the data link bandwidth that "can reduce the RPA operator's temporal resolution, spatial resolution, and color discrimination capabilities" (Merlin, 2013, p. 127).

Frequently, highly experienced fixed-wing pilots (to include this author) with several thousand flight hours accumulated in various types of aircraft flown in numerous flight envioronments become task saturated very rapidly when initially flying a MQ-1 or MQ-9 UAS. Experience flying the RPA via camera without the usual weather cues, the delayed control response, the lack of tactile feel, and the lack of peripheral vision reinforced the importance of CRM and the coordination required with the camera operator to successfully fly the RPA. The need for CRM and teamwork in UAS flight operations was critical. Merlin (2013) emphatically stated that "Good training and teamwork are critical to the safe operation of remotely piloted vehicles" (p. 130).

Sharma and Chakravarti (2005) listed loss of situational awareness as the second most prevalent accident risk factor in their five-accident review. As noted in Table 3, UAS pilots' duty periods are long and consist of monitoring the flight trajectory performance of the highly automated vehicle. Sharma and Chakravarti (2005) found that pilots lost concentration resulting in diminished situational awareness. Given the technological environment created by highly automated systems, CRM crew training focused on human in-the-loop protocols will be a foundational element to teach crews the importance of maintaining situational awareness during large civil commercial UAS operations.

\section{Threat and Error Management}

Threat and Error Management (TEM) in flight operations is comprised of three elements: threats, errors, and undesired aircraft state (SKYbrary, 2017). The basic premise of TEM is that flight crews will manage threats and commit errors as part of normal flight operations. The mismanagement of the threats and errors might precipitate an undesired aircraft state. As a consequence, recognizing threats and acting appropriately to trap errors prior to attaining an undesired aircraft state is critical to safe flight operations for all operations to include UAS flight operations.

Threat. A threat is "an event or error that occurs beyond the influence of the flight crew, increases operational complexity, and which must be managed to 
maintain the margins of safety" (SKYbrary, 2017, para. 2.0). It usually constitutes the first step in the sequence, which if not properly managed, leads to an operational error and a potential subsequent undesired aircraft state. Anticipated threats are threats posed by known hazards such as adverse weather or traffic congestion for manned aircraft. Unmanned aircraft threats might consist of weather events that exceed the certification limitations of the aircraft. Unexpected threats occur due to in-flight malfunctions that require flight crew skill and knowledge to achieve a solution. In unmanned aircraft operations, lost communications link or loss of visual contact constitute unexpected threats. A third type of threat is the latent threat. These types of threats potentially stem from design deficiencies or inadequate operational policy planning. Identifying and managing threats is a building block for error management and prevention of the aircraft attaining an undesired aircraft state (SKYbrary, 2017).

In each accident of Neff's (2016) cross-case analysis, a misidentified and inappropriately managed threat resulted in an error that was not corrected and precipitated the undesired aircraft state and loss of the RPA. In the April 26, 2006 Nogales, AZ accident, the threat of a loss of the flight display for the untrained and unsupervised pilot created errors in decision making and procedural execution that eventually led to the crash.

Error. In the context of TEM, errors are defined as "actions or inactions by the flight crew that lead to deviations from organisational [sic] or flight crew intentions or expectations" (SKYbrary, 2017, para. 3). Errors are the next step in the sequence occurring as a result of a mismanaged threat. The concept of error trapping (i.e., detection and response) is as critical as the concept of understanding error cause and perpetuation (SKYbrary, 2017).

There are three types of errors (a) aircraft handling errors, (b) procedural errors, and (c) communications errors. Aircraft handling errors occur when the flight crew mishandles the aircraft in some manner such as exceeding aircraft design limitations, selecting an incorrect automation state, or being unable to fly the aircraft within the operational parameters. With reference to Table 2, Neff's (2016) four-accident case study found that $18 \%$ of the accident risk can be ascribed to skill-based errors in aircraft handling.

Procedural errors occur with flight crew failure to properly follow standard operating procedures, failure to use such aids as checklists, briefings, and callouts (SKYbrary, 2017). Events of the Seychelles Islands, April 4, 2012 accident highlight the lack of procedural discipline when the mission pilot shut down the engine inadvertantly, both crewmembers failed to complete the landing procedures, and landed the aircraft with the landing gear retracted.

Communication errors occur when the flight crew misunderstands or misapplies an external instruction or when the flight crew misinterprets internal communication between themselves (SKYbrary, 2017). As referenced in Table 2, 
Neff's (2016) four-accident cohort study ranked communications errors high with a $8 \%$ probability that they were a causal factor. Sharma and Chakravarti (2005) ranked communications as the seventh leading accident risk factor in their 5accident study.

Undesired Aircraft State. The TEM context defines undesired aircraft state as "flight induced aircraft position or speed deviations, misapplication of flight controls, or incorrect systems configuration, associated with a reduction in margins of safety" (SKYbrary, 2017, para. 4). Undesired aircraft state often is the result of a misidentification of a threat with the resultant error in flight crew management of the threat.

Undesired aircraft states fall into three categories. The first category consists of aircraft handling errors such as loss of aircraft control, operation of the aircraft outside of the design envelope, and unstable approaches. The second category involves flight crew ground navigation errors such as following an incorrect taxi route or taxiing to an incorrect spot or gate. The third undesired aircraft state is the result of the flight crew misconfiguring the aircraft for the intended operation (SKYbrary, 2017). A landing gear up landing or a takeoff with an incorrect weight and balance configuration are examples of misconfigured aircraft.

The tenets of CRM encompass several countermeasures to ensure that threats are recognized, errors are trapped before they occur, and the undesired aircraft state is not attained. As a priority, operators must train and emphasize the application of standard operating procedures (SOP) by flight crews. SOP are developed from best practices learned over time and represent the best risk mitigations for potential threats. According to SKYbrary (2017), 70\% of flight crew activity is devoted to TEM countermeasures. In addition to the application of SOP, cross-checking of crew actions by other crewmembers, re-evaluating decisions, encouraging questions, establishing protocols for conflict resolution, encouraging crewmember advocacy, and using standard callouts constitute TEM mitigations.

The planning, execution, and review of TEM countermeasures (SKYbrary, 2017) are required flight crew skills. Flight operational safety is the result of a high functioning flight crew team utilizing the tenets of CRM in a systemic based operational tempo relying on SOP, excellent communications skills, crew workload management, maintenance of situational awareness, and timely application of TEM countermeasures. 


\section{Conclusions and Future Research}

\section{Conclusions}

The overall purpose of this article was to research CRM operational tenets for integration into a safety management system construct for future large civil commercial UAS operations that when applied as standard operating procedures will contribute to operational safety in the joint use NAS. Both Neff's (2016) fouraccident case study and Sharma and Chakravarti's (2005) five-accident study demonstrated that inadequate leadership skills at the corporate management level and skill-based errors at the operational level compounded the soft-skill errors of decision making, workload management, and communication. Additionally, Table 2 and Table 3 indicate inadequate workload management and loss of situational awareness contributed to the nine accidents studied. In Figure 3, Rudari, et al. (2015) demonstrated that an operational philosophy emphasizing the principles of CRM in training supported the implementation of safety procedures and operational best practices in daily flight operations. The result was fewer operational accidents during the period 1998 to 2013. As an overarching operational philosophy, a vibrant safety management system incorporating CRM as one element countering human factors errors must be supported by the accountable executive and by senior leadership.

\section{Future Research}

The arena of future UAS commercial flight operations presents numerous research opportunities. Further fatigue management research will be driven by the prospective operating environment of long duration missions. Similarly, humanmachine interface attention span research to improve the efficiency and effectiveness of automated systems management will be a requirement of future UAS flight operations. Research into the effectiveness and feasibility of promulgating risk-based regulation applicable to all operators by national aviation authorities will be required to ensure safe integration of UAS operations into the NAS. In addition to research in the operational area, studying the development of best CRM practices and the implementation of threat and error management principles inherent in CRM is necessary to counter potential human error in the design, manufacturing, operation, and maintenance of UAS. This future research will be necessary to meet the public's demand and expectations of safety in the new unmanned sector of aviation. 


\section{References}

Arjomandi, M. (2007). Classification of unmanned aerial vehicles. The University of Adelaide, Australia, Mechanical Engineering. Retrieved from https://s3.amazonaws.com/academia.edu.documents/ 29666442/group9.pdf

Conner, M. (2015, November 16). NASA Armstrong fact sheet: Ikhana Predator $B$ unmanned science and research aircraft system. Retrieved from https://www.nasa.gov

Cusick, S. K., Cortes, A. J., \& Rodrigues, C. (2017). Commercial aviation safety (6th ed.). New York,NY: McGraw Hill Education.

Dahlstrom, N., Laursen, J., \& Bergstrom, J. (2008). Crew resource management, threat and error management, and assessment of CRM skills. Lund, Sweden: Swedish Civil Aviation Authority. Retrieved from https://www.researchgate.net

Echternacht, K. L. (2012). Aircraft accident investigation board (MQ-9A, T/N 05000102). Wright-Patterson Air Force Base, OH. United States Air Force. Retrieved from http://www.accaf.mil/library/foia

Federal Aviation Administration. (2004). AC 120-51E: Crew resource management training. Washington, DC. Author. Retrieved from http://www.faa.gov

Federal Aviation Administration. (2018a). 14 CFR part 107 small unmanned aircraft systems. Washington, DC. Author. Retrieved from https://www.ecfr.gov

Federal Aviation Administration. (2018b). UAS integration pilot program. Retreived from https://www.faa.gov/uas/programs_partnerships/ uas_integration_pilot_program

Grace, E. C. (2012). Accident investigation board (MQ-9, T/N 09-004065). Nellis Air Force Base, NV: United States Air Force. Retrieved from http://www.accaf.mil/library/foia

Helmreich, R. L., Merritt, A. C., \& Wilhelm, J. A. (1999). The evolution of crew resource management training in commercial aviation. International Journal of Aviation Psychology, 9(1), 19-32. doi: 10.1207/s15327108ijap0901 2

Jaquish, D. W. (2011). Aircraft accident investigation board (MQ-9A, T/N 064105). Wright-Patterson Air Force Base, OH: United States Air Force. Retrieved from http://www.accaf.mil/library/foia

Kooser, A. (2018, June 13). NASA unmanned Ikhana aircraft makes history flying without escort. c/net. Retrieved from https://www.cnet.com/news 
Lacagnina, M., Rosenkrans, W., Werfelman, L., \& Darby, R. (2003). The human factors implications for flight safety of recent developments in the airline industry. Flight Safety Digest, 22(3-4), 1-78.

McEwan, D., Ruissen, G. R., Eys, M. A., Zumbo, B. D., \& Beauchamp, M. R. (2017). The effectiveness of teamwork training on teamwork behaviors and team performance: A systematic review and meta-analysis of controlled interventions. PLos ONE 12(1), doi: 10.1371/journal.

Merlin, P. W. (2013). Manning the unmanned, humans in the loop. In Crash course: Lessons learned from accidents involving remotely piloted and autonomous aircraft. Retreived from https://www.nasa.gov/pdf/ 732725main_crash_course-ebook.pdf

National Transportation Safety Board. (2007). CHIO6MA121: File No 22329. Washington, D.C. National Transportation Safety Board. Retrieved from http://www.ntsb.gov

Neff, P. (2016). Unmanned aircraft systems - The mitigation of human factors errors through training (Doctoral Dissertation). 10140039: Retrieved from ProQuest Dissertations Publishing.

Northon, K. (2018, June 13). NASA's Ikhana could fly in the NAS unaccompanied in 2018. NASA Press Release. Retrieved from https://www.nasa.gov/ press-release

Rudari, L., Spence, T., Sperlak, L., Geske, R., Walala, M., Brown, P., . . Thanos, M. (2015). The transformation of CRM-based training and it [sic] effects on aviation safety in the U.S. from 1960 to 2013. Retrieved from https://flight Safety.org

Ryan, W., \& Larrow, J. (2017). FAA building blocks leading to UAS integration, airworthiness and operational integration. Russian FederalAir Transport Agency (FATA) (p. 11). Moscow, RU.

Ryan, W. (2017). Unmanned systems certification. Committee on Assessing the Risks of Unmanned Aircraft Systems (UAS) Integration. Washington, D.C: National Academies of Science. Retreived from http://sites.nationalacademies.org/DEPS/ASEB/DEPS_180887

Sharma, S., \&. Chakravarti, D. (2005). UAV operations: An analysis of incidents and accidents with human factors and crew resource management perspective. Indian Journal of Aerospace Medicine, 49(1), 29-36. Retrieved from medind.nic.in

SKYbrary. (2017). Threat and error management (TEM) in flight operations. Retrieved from http://www.skybrary.aero

SKYbrary. (2018). Crew resource management. Retrieved from http://www.skybrary.aero 
Trump, D. (2017, October 25). Presidential memorandum for the Secretary of Transportation. Retrieved from https://www.whitehouse.gov/presidentialactions/presidential-memorandum-secretary-transportation

Uzialko, A. C. (2018, May 10). 10 cool commercial drone uses coming to a sky near you. Business News Daily. Retrieved from https://www.businessnewsdaily.com

United States Congress. (2012, February). Public Law 112 - 95 - Feb. 14, 2012: Subtitle B--Unmanned Aircraft Systems. Retrieved from https://www.faa.gov

Wheeler, W. (2012, February 28). The MQ-9's cost and performance. Retrieved from nation.time.com/2012/28/2-the-mq-9s-cost-and-performance

Wiegman, D. A., \& Shappell, S. A. (2003). A human error approach to aviation accident analysis: The Human Factors Analysis and Classification System. Burlingto, VT: Ashgate Publishing Company. 